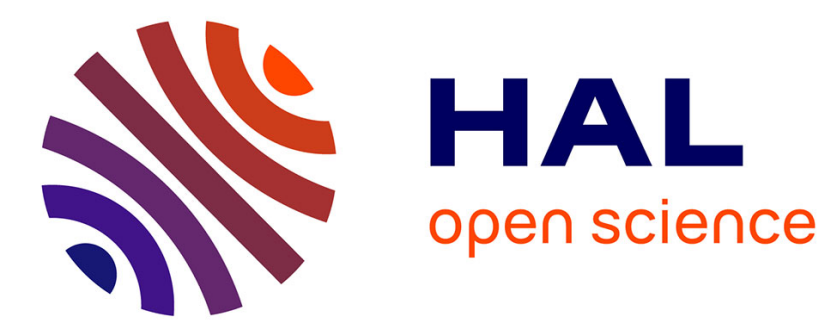

\title{
Direct $\mathrm{Bi} 3+-\mathrm{Bi} 3+$ contacts mediated by lonepairs in the HP-BiNiO(PO4) polymorph
}

Marie Colmont, Anastasiya Zadoya, Céline Darie, Cyril Domingos, Bastien Leclercq, Olivier Mentré

\section{- To cite this version:}

Marie Colmont, Anastasiya Zadoya, Céline Darie, Cyril Domingos, Bastien Leclercq, et al.. Direct Bi $3+-\mathrm{Bi} 3+$ contacts mediated by lonepairs in the HP-BiNiO(PO4) polymorph. CrystEngComm, 2021, 23 (29), pp.5124-5130. 10.1039/d1ce00802a . hal-03438976

\section{HAL Id: hal-03438976 https://hal.science/hal-03438976}

Submitted on 22 Nov 2021

HAL is a multi-disciplinary open access archive for the deposit and dissemination of scientific research documents, whether they are published or not. The documents may come from teaching and research institutions in France or abroad, or from public or private research centers.
L'archive ouverte pluridisciplinaire HAL, est destinée au dépôt et à la diffusion de documents scientifiques de niveau recherche, publiés ou non, émanant des établissements d'enseignement et de recherche français ou étrangers, des laboratoires publics ou privés. 


\title{
Direct $\mathrm{Bi}^{3+}-\mathrm{Bi}^{3+}$ contacts mediated by lonepairs in the HP- BiNiO(PO4) polymorph
}

\author{
Marie Colmont, ${ }^{1 *}$ Anastasiia Zadoya, ${ }^{1}$ Céline Darie,${ }^{2}$ Cyril Domingos, ${ }^{2}$ Bastien Leclercq,,${ }^{1}$ and Olivier \\ Mentré ${ }^{1}$ \\ ${ }^{1}$ Université Lille, CNRS, Centrale Lille, ENSCL, Université Artois, UMR 8181, Unité de Catalyse et Chimie du Solide, Lille, \\ F-59000, France. \\ ${ }^{2}$ Université Grenoble Alpes et CNRS, Institut NEEL, F-38042 Grenoble, France \\ Supporting Information Placeholder
}

\begin{abstract}
A high-pressure polymorph of $\mathrm{BiNiPO}_{5}$ was prepared at $5 \mathrm{GPa}$. In the $\mathrm{HP}$ phase, the parent $1 \mathrm{D}-[\mathrm{BiNiO}]^{3+}$ trans chains of edge-sharing $\mathrm{O}\left(\mathrm{Bi}_{2} \mathrm{Ni}_{2}\right)$ oxo-centered tetrahedra are conserved but reorganized into a more compact crystal-structure. It returns short $\mathrm{Bi}-\mathrm{Bi}$ contacts $(3.42 \AA)$ with interacting lone pair (LP) electrons via weakly bonding $\sigma$ bond. The main density of states topology is preserved bringing a calculated bandgap about $3.45 \mathrm{eV}$ for the HP-form against $3.52 \mathrm{eV}$ for the ambient pressure (AP) form. So do the magnetic properties mainly hold by the 1D subunits, which order antiferromagnetically at $T_{\mathrm{N}}=16.3 \mathrm{~K}$ against 17.5 $\mathrm{K}$ in $\mathrm{AP}_{-} \mathrm{BiNiPO}_{5}$. Our work attests the oxo-centered polyhedra role and principles, prompt to form the robust framework of the 3D-lattice able to survive structural transformation in extreme conditions.
\end{abstract}

The large family of bismuth metal (M) phosphate has been intensively investigated during the last decades.[1] The quasi-systematic polymerization of $\mathrm{O}(\mathrm{Bi}, \mathrm{M})_{4}$ anti-tetrahedra $(\mathrm{A}-T d)$ into versatile (0D to 3D) types of structural units is allowed by the flexibility of the $\mathrm{A}-T d \mathrm{~s}$ able to co-admit, $\mathrm{Bi}^{3+}$ ions, alkali, alkali-earths, transition metals or heavy metals... into more or less ordered frameworks. [2] Among the simplest ordered terms, the $\mathrm{BiMO}\left(\mathrm{XO}_{4}\right)$ and $\mathrm{BiM}_{2} \mathrm{O}_{2}\left(\mathrm{XO}_{4}\right)$ series $(\mathrm{M}=\mathrm{Ca}, \mathrm{Cd}, \mathrm{Co}, \mathrm{Mg}, \mathrm{Mn}, \mathrm{Ni}, \mathrm{Pb}$ and $\mathrm{X}=\mathrm{As}$, $\mathrm{P}, \mathrm{V})$ [1] were mainly studied for their optical [3], [4] or magnetic properties. [5]-[8] For instance $\mathrm{BiCu}_{2} \mathrm{O}_{2}\left(\mathrm{PO}_{4}\right)$ (BCPO) is a frustrated two-leg $\mathrm{S}=1 / 2$ ladder with a cascade of field induced transitions.[9], [10] Recently, high-pressure high-temperature (HP-HT) transformation was used to stabilize a HP polymorph at $5 \mathrm{GPa}$ and $800{ }^{\circ} \mathrm{C}$. In the HP-form, the 1D-ladder topology and spin-gap survive although the effect of the twist between next ladders modify significantly some of the interchain exchanges, see [11].

These results lead us to explore other related systems through the prism of HP-HT route. Here, the concerned $\mathrm{BiMO}\left(\mathrm{XO}_{4}\right)$ family of compounds was largely detailed in [3]. Their crystal structures display cis- or trans- $1 \mathrm{D}$ oxo-centered $[\mathrm{OBiM}]^{3+}$ single-chains built on $\left(\mathrm{OBi}_{2} \mathrm{M}_{2}\right) \mathrm{A}-\mathrm{Td}$ s sharing $\mathrm{M}-\mathrm{Bi}$ (trans- case) edges. Only BiCaVO [12], [13] and $\mathrm{BiCdVO}_{5}$ [14] have $\mathrm{Ca}^{2+}$ and $\mathrm{Cd}^{2+}$ in cis position which make them singular examples. In any case, the $\mathrm{XO}_{4}$ surround the chains. Both the cis- vs. trans-configurations and cationic steric effects for instance of the $\mathrm{XO}_{4}$ groups (vol. $\mathrm{PO}_{4}<\mathrm{AsO}_{4}<\mathrm{VO}_{4}$ ), may change the crystal symmetry. Most compounds are monoclinic (S.G. $P 2_{1} / n$ ) [3] (except $\mathrm{BiCaVO}_{5}$ that is orthorhombic, S.G. Pbca) becomes triclinic (S.G. $P-1)$ in case of big cations $\left(\mathrm{Pb}^{2+}\right.$ or $\mathrm{As}^{5+}$ for example), [15], [16] interpretable from chemical pressure effect. Among the series, the $\mathrm{M}=\mathrm{Ni}$ compound $\mathrm{BiNiPO}_{5}$ (denoted APBNPO below, where AP stands for ambient pressure) crystallizes in the $P 2{ }_{1} / n$ space group. [17] Its crystal structure is shown on Fig. 1a with details on the $1 \mathrm{D}[\mathrm{OBiNi}]^{3+}$ oxo-centered trans-chains surrounded by isolated phosphates. A snapshot of the Electron Localization Function (ELF) obtained from DFT calculations, shows evidence of the $\mathrm{Bi}^{3+}$ electronic lone pair stereoactivity mainly lying in the $a c$ plane in the free interchain space in the AP form.

In the oxo-centered chains, $\mathrm{Ni}^{2+}$ cations being in trans positions, they share an $\mathrm{O}-\mathrm{O}$ edge leading to dominant ferromagnetic (FM) $\mathrm{Ni}-\mathrm{O}-\mathrm{Ni}$ super-exchanges $\left(\mathrm{Ni}-\mathrm{O}-\mathrm{Ni}=99.9^{\circ}\right)$ well predicted by Kanamori-Goodenough rules.[18] The magnetic structure refined from powder neutron data and the analysis of the magnetic phase diagram confirms that the antiferromagnetic (AFM) ordering below $T_{\mathrm{N}}=17.5 \mathrm{~K}$ results for the competition between a large number of inter and intra-chains Ni-O-O-Ni super super-exchanges (SSEs). [5] Keeping this specificity in mind, the HP-HT synthesis route was used to reorder these units HP-BNPO similarly to the AP-BCPO $\rightarrow$ HP-BCPO transformation.[11] This paper deals with the HP/HT modification of $\mathrm{BiNiPO}_{5}$, its structural and magnetic investigations and the consequences on $\mathrm{Bi}-\mathrm{Bi}$ bonding.

Experimental section

Synthesis

Single phase HP-BNPO material was obtained by HP/HT treatment of AP-BNPO at $5 \mathrm{GPa}$ and $600{ }^{\circ} \mathrm{C}$. polycrystalline AP-BNPO was preliminary prepared using the method given in [17] using a stoichiometric mixture of $\mathrm{Bi}_{2} \mathrm{O}_{3}, \mathrm{NiO}$ and $\left(\mathrm{NH}_{4}\right) \mathrm{H}_{2} \mathrm{PO}_{4}$, treated at $850^{\circ} \mathrm{C}$. The sample was further loaded in a Platinum capsule sealed afterwards and squeezed in a belt-type apparatus system. Details about the press and synthesis conditions are presented in ref [11].

Structural job

Powder X-ray diffraction (XRD) data were collected at room temperature in the range of $2 \theta=5-120^{\circ}$, with 0.02 step and using a D8 Advance Bruker AXS diffractometer in Bragg Brentano geometry equipped with a $1 \mathrm{D}$ LynxEye detector. The Rietveld refinement was performed using JANA2006. [19]

High-Temperature XRD (HT-XRD) was done using a Rigaku SMARTLAB multipurpose diffractometer $(9 \mathrm{~kW}$ rotating anode) in Bragg-Brentano reflection beam mode (with a PSD 1D detector DTEX) delivering $\mathrm{CuK} \alpha$ radiation $(\lambda=1.5418 \AA)$. High temperature XRD measurements were done loading the sample in an Anton 
Paar DHS1100 hot plate stage between room temperature and $850{ }^{\circ} \mathrm{C}$, heating rate $10^{\circ} \mathrm{C} / \mathrm{min}$. Omega-2theta scans were performed between $10^{\circ}$ and $90^{\circ}$ with a scan speed of $10 \% / \mathrm{min}$.

\section{Magnetic properties}

Magnetic data were measured on a Physical Property Measurement System (PPMS) Dynacool (9 T) system from Quantum Design. Typical measurements using zero field cooling (ZFC) and field cooling (FC) procedures were performed at $0.1 \mathrm{~T}$. The Curie Weiss fit was performed in the temperature range of 50 to $300 \mathrm{~K}$. Field dependence of the magnetization was also collected at 2, 50, 100 and $300 \mathrm{~K}$.

\section{Calculation}

DFT calculations were performed using the projector augmentedwave (PAW) method [20] implemented in the Vienna ab-initio Simulation Package (VASP) [21], with the full-potential local-orbital scheme (FPLO9.00-33) [22]. We used the generalized gradient approximation (GGA) for electron exchange and correlation corrections [23] applying the local density approximation (LDA + $\mathrm{U}, \mathrm{U}=7 \mathrm{eV}$ ).

The cutoff energy for the plane wave expansion was $550 \mathrm{eV}$ and reciprocal-space integration was performed on dense Monkhorstpack meshes $(21 \times 21 \times 21)$ for HP-BNPO and $(10 \times 14 \times 16)$ for BNPO-AP. It included 4631 (AP, $P 2{ }_{1} / n$ ) and 1124 (HP, $P-1$ ) points in the symmetry-irreducible part of the first Brillouin zone for the crystallographic unit cell. Convergence criteria of $10^{-6}$ and $10^{-3}$ were set for convergence of the electronic and cycles and ionic relaxation, respectively. The electronic localization function (ELF) and the density of states of $\mathrm{Bi}, \mathrm{O}$ and $\mathrm{P}$ atoms are deduced from the GGA-only calculations. For bond analysis, after plane-wave DFT calculations, the LOBSTER package [24] allows extraction of the project and Integrated Crystal Orbital Hamilton population p-COHP and I-COHP. Tight Binding Extended Hückel (TBEH) calculations have been performed using the Samoa package. [25]

Results and discussion

Crystal structure

HP-BPNO was found to be stable after releasing first temperature and then pressure. Its XRD pattern (see Fig. S1 in ESI) differs from the one of the AP-BNPO but is reminiscent of the $\mathrm{BiNiO}\left(\mathrm{AsO}_{4}\right)$ phase / BNAO. [16] It was fully indexed in the triclinic unit cell $\mathrm{a}=$ $7.4211(4), b=6.5606(4), c=5.1633(3) \AA, \alpha=83.817(2), \beta=$ $110.727(2)$ and $\gamma=123.412(2)^{\circ}$. The structure was refined in the $P-1$ space group and validates the isomorphism between HP-BNPO and BNAO. We note that similar relationship was established between $\mathrm{HP}-\mathrm{BCPO}$ and $\mathrm{BiCu}_{2} \mathrm{O}_{2}\left(\mathrm{AsO}_{4}\right) / \mathrm{BCAO}$. [11] It is driven by a unit-cell compression by $-1.7 \%$ from the $\mathrm{AP}$ phase $\left(\mathrm{V}_{\mathrm{AP}}=\right.$ $99.17 \AA^{3}$ vs $V_{\text {HPeq }}=97.52 \AA^{3}$ ). The Rietveld refinement was performed starting from the BNAO model and further finalized imposing $\mathrm{P}-\mathrm{O}$ distance restrictions. All oxygen ADP parameters were fixed to 0.012 . It results in the final agreement factors $R_{p}=0.0281$, $\mathrm{wR}_{\mathrm{p}}=0.0376$. The experimental versus calculated XRD patterns are shown on Fig. 1c. The main interatomic distances vary from 2.105 to $2.492 \AA$ for $\mathrm{Bi}-\mathrm{O}$, from 1.832 to $2.282 \AA$ for $\mathrm{Ni}-\mathrm{O}$ and from 1.424 to $1.593 \AA$ for P-O. The atomic coordinates and main distances are gathered in Tables 1 and 2. In Table 1, the refined coordinates are compared to those obtained from DFT-relaxed structure. All the information regarding the refinement are summarized in Table S1 in the ESI. Finally, the crystal structure is shown on Fig. 1b. It is striking that the oxo-centered chains are conserved within nearly-unmodified geometries, which validates their robustness, and principles as rigid structural sub-units. [1] Similar conclusions than in the HP-BCPO study can be proposed. In both cases, the physical pressure compensates the chemical pressure induced by the substitution of $\mathrm{P}^{5+}$ by bigger $\mathrm{As}^{5+}\left(\mathrm{r}_{\mathrm{P} 5+}-\mathrm{r}_{\mathrm{As} 5+}: 0.17-\right.$ $0.33 \AA$ ). In that sense, it is possible to foresee the formation of HP$\mathrm{BiM}_{2} \mathrm{O}_{2}\left(\mathrm{PO}_{4}\right)$ and $\mathrm{HP}-\mathrm{BiMO}\left(\mathrm{PO}_{4}\right)$ into crystal structures corresponding to the AP-arsenate polytypes.

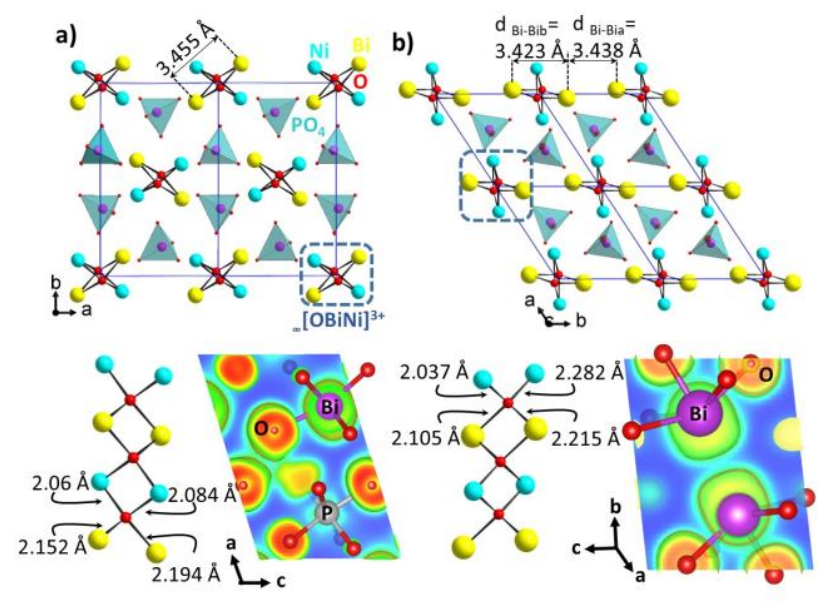

c)

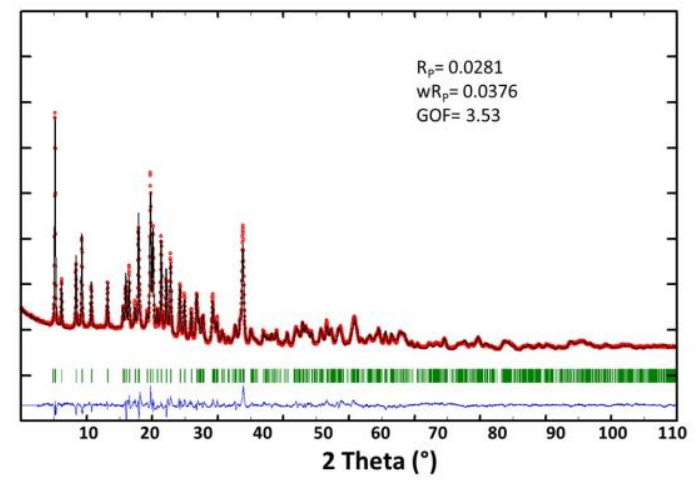

Fig. 1. Projection along the $c$-axis of the a) AP-BNPO, and b) HPBNPO. Snapshots of the ELF function with evidence of the $\mathrm{Bi}^{3+}$ electronic lone pair from DFT calculations for the AP and HP forms of $\mathrm{BiNiO}\left(\mathrm{PO}_{4}\right)$. The representations were drawn at $\eta(\mathrm{r})=0.4$ isosurface c) Powder XRD Rietveld refinement: the experimental (red) and calculated (black) patterns are superimposed; the difference curve and Bragg positions are respectively represented in blue and green.

Bi-Bi interaction

In the HP-BNPO crystal structure, the Bi-Bi distances between next $[\mathrm{BiMO}]^{3+}$ units $\left(\mathrm{d}\left(\mathrm{Bi}-\mathrm{Bi}_{\mathrm{a}}\right)=3.438(3)\right)$ and inside them $(\mathrm{d}(\mathrm{Bi}-\mathrm{Bi} \mathrm{b})=$ 3.423(3) $\AA$ ) are surprisingly almost identical as observed in Fig. $1 b)$, in absence of intermediate $\sigma_{(\mathrm{Bi}-\mathrm{O})}$ bonds for $\mathrm{Bi}-\mathrm{Bi}_{\mathrm{a}}$. Here, such "short" Bi-Bi contact mediated by LP electrons pointing towards each other returns an intriguing situation and questions about 
the occurrence of a bonding scheme. Indeed, looking at the APBNAO isomorph yields a similar situation with even shorter distances of 3.4126(8) A. [15]

Table 1. Atomic coordinate comparison between Rietveld refinement and relaxed structure from DFT calculation.

\begin{tabular}{|c|c|c|c|c|c|}
\hline $\begin{array}{l}\text { Atom } \\
\text { (Riet) } \\
\text { (Relaxed) }\end{array}$ & $\begin{array}{l}\mathbf{X} \\
X\end{array}$ & $\begin{array}{l}Y \\
Y\end{array}$ & $\begin{array}{l}\mathbf{Z} \\
\mathbf{Z}\end{array}$ & $\mathbf{U}_{\text {eq }}$ & $\begin{array}{l}\text { BVS } \\
\text { sum }\end{array}$ \\
\hline Bi1 & $0.9552(3)$ & $0.2302(3)$ & $0.8972(3)$ & $0.0092(5)$ & $2.96(6)$ \\
\hline & 0.9563 & 0.2342 & 0.8956 & & \\
\hline Ni1 & $\begin{array}{l}0.7250(8) \\
0.7270\end{array}$ & $\begin{array}{l}0.8638(7) \\
0.8669\end{array}$ & $\begin{array}{l}0.3230(9) \\
0.3277\end{array}$ & $0.049(17)$ & 2.11(3) \\
\hline P1 & $\begin{array}{l}0.3761(10) \\
0.6134\end{array}$ & $\begin{array}{l}0.6980(11) \\
0.2996\end{array}$ & $\begin{array}{l}0.6492(12) \\
0.6642\end{array}$ & $0.013(2)$ & $5.22(11)$ \\
\hline $\mathrm{O} 1$ & $\begin{array}{l}0.926(2) \\
0.9545\end{array}$ & $\begin{array}{l}0.929(2) \\
0.9503\end{array}$ & $\begin{array}{l}0.7331(14) \\
0.7170\end{array}$ & 0.0012 & $2.26(5)$ \\
\hline $\mathrm{O} 2$ & $\begin{array}{l}0.236(2) \\
0.2101\end{array}$ & $\begin{array}{l}0.791(2) \\
0.7765\end{array}$ & $\begin{array}{l}0.614(2) \\
0.6103\end{array}$ & 0.0012 & $2.27(9)$ \\
\hline $\mathrm{O} 3$ & $\begin{array}{l}0.2954(19) \\
0.2208\end{array}$ & $\begin{array}{l}0.4579(12) \\
0.4382\end{array}$ & $\begin{array}{l}0.757(2) \\
0.7411\end{array}$ & 0.0012 & $2.12(4)$ \\
\hline $\mathrm{O} 4$ & $\begin{array}{l}0.458(2) \\
0.4261\end{array}$ & $\begin{array}{l}0.708(2) \\
0.7025\end{array}$ & $\begin{array}{l}0.3990(19) \\
0.3897\end{array}$ & 0.0012 & $1.74(5)$ \\
\hline O5 & $\begin{array}{l}0.5919(16) \\
0.6129\end{array}$ & $\begin{array}{l}0.8812(16) \\
0.8811\end{array}$ & $\begin{array}{l}0.9002(18) \\
0.4002\end{array}$ & 0.0012 & $1.90(3)$ \\
\hline
\end{tabular}

$* \mathrm{U}_{\text {eq }}$ oxygen are fixed

Table 2. Typical interatomic distances in HP-BNPO, the DFTrelaxed structures are given in italic.

\begin{tabular}{|c|c|c|c|c|c|}
\hline \multicolumn{2}{|l|}{ Atoms } & $\begin{array}{l}\text { Riet. d, } \AA \\
\text { Rel. } d, \AA\end{array}$ & \multicolumn{2}{|c|}{ Atoms } & $\begin{array}{l}\text { Riet. d, } \AA \\
\text { Rel. } d, \AA\end{array}$ \\
\hline \multirow[t]{11}{*}{ Bil } & $\mathrm{O} 1$ & $2.105(16)$ & Ni1 & O1 & 2.037(8) \\
\hline & $\mathrm{O} 1$ & $2.215(11)$ & & O1 & $2.282(14)$ \\
\hline & & 2.3080 & & & 2.0687 \\
\hline & O5 & $2.395(9)$ & & $\mathrm{O} 2$ & $2.165(16)$ \\
\hline & & 2.3289 & & & 2.1552 \\
\hline & $\mathrm{O} 3$ & $2.457(13)$ & & $\mathrm{O} 3$ & $2.107(13)$ \\
\hline & & 2.3434 & & & 2.0701 \\
\hline & $\mathrm{O} 2$ & $2.492(10)$ & & $\mathrm{O} 4$ & $1.833(15)$ \\
\hline & & 2.4520 & & & 2.0083 \\
\hline & O4 & $3.134(16)$ & & O5 & $2.073(10)$ \\
\hline & & 2.9329 & & & 2.0551 \\
\hline \multirow[t]{4}{*}{$\overline{\mathrm{P} 1}$} & $\mathrm{O} 2$ & $1.42(2)$ & P1 & O4 & $1.594(16)$ \\
\hline & & 1.5736 & & & 1.5429 \\
\hline & $\mathrm{O} 3$ & $1.469(10)$ & & O5 & $1.561(8)$ \\
\hline & & 1.5549 & & & 1.5550 \\
\hline \multirow[t]{2}{*}{$\mathrm{Ni}$} & $\mathrm{Ni}$ & $3.2533(65)$ & & & \\
\hline & & 3.2255 & & & \\
\hline \multirow[t]{2}{*}{$\mathrm{Bi}$} & $\mathrm{Bib}$ & $3.423(3)$ & $\mathrm{Bi}$ & $\mathrm{Bia}$ & $3.438(3)$ \\
\hline & & 3.4019 & & & 3.4656 \\
\hline
\end{tabular}

The external $\mathrm{Bi}-\mathrm{Bi}$ contacts are usually longer as compared to most compounds of the $\mathrm{Bi}_{2} \mathrm{O}_{3}-\mathrm{MO}-\mathrm{X}_{2} \mathrm{O}_{5}$ systems in which they are mediated by counter $\mathrm{XO}_{4}$ groups, or across ionic interleaves $(4.5 \AA$ in $\mathrm{BiOF}$ ) or even across van-der-Waals gap, as for $\mathrm{Pb}^{2+}$ in tetragonal $\mathrm{PbO}(\mathrm{d}(\mathrm{Pb}-\mathrm{Pb})=3.84 \AA)$. However, slightly longer $\mathrm{Bi}-\mathrm{Bi}$ contacts are found in some counter-examples, such as $3.54 \AA$ in
$\mathrm{Bi}_{4} \mathrm{MgO}_{4}\left(\mathrm{PO}_{4}\right)_{2}$, see Fig. 2, but interacting [Bi] sublattice is arranged in a compact-shifted manner such that the LP's do not face each other. [26]

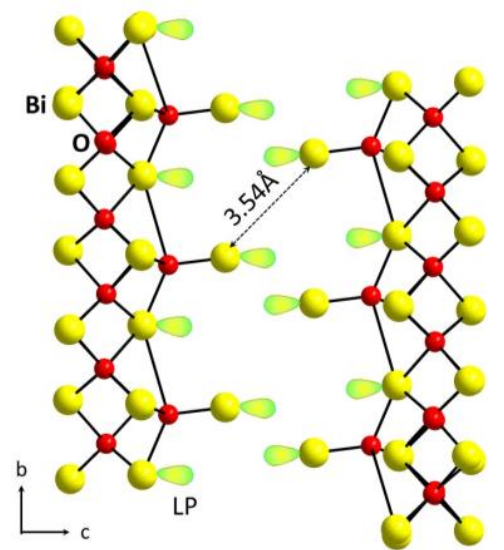

Fig. 2. Long Bi-Bi contacts in $\mathrm{Bi}_{4} \mathrm{MgO}_{4}\left(\mathrm{PO}_{4}\right)_{2}$ with non-facing Bismuth Lone Pairs.

For comparison with anionic or metal Bi more prompt to covalent bonding, this relative short distance across two $\mathrm{Bi}^{3+}$ lone pairs in absence of anionic media is longer by $8 \%$ from those found in the naked $\mathrm{Bi}_{2}{ }^{4-}$ anions found in $\mathrm{Ca}_{11} \mathrm{Bi}_{10}(3.15 \AA)$,[27] by $11 \%$ compared to the shortest $\mathrm{Bi}-\mathrm{Bi}$ bonds in rhombohedral metal bismuth (3.06 $\AA$ ), [28] by $13 \%$ from the Bi-Bi dimers with single bonds of in the substituted $\mathrm{Ph}_{4} \mathrm{Bi}_{2}$,[29] and by $19 \%$ from what found in doubly bonded $\left(\mathrm{Bi}_{2}\right)^{2-}$ of $(\mathrm{K} \text {-crypt })_{2}\left(\mathrm{Sn}_{2} \mathrm{Bi}_{2}\right)$. [30] In a preliminary approach, we better understood the role of the lone pair by calculation of the molecular orbitals (M.O.) by TBEH.[20], for $\left[\mathrm{BiO}_{3}\left(\mathrm{PO}_{4}\right)\right]^{6-}$ and dimeric $\left[\mathrm{Bi}_{2} \mathrm{O}_{6}\left(\mathrm{PO}_{4}\right)_{2}\right]^{12-}$ isolated units, chosen to take into account direct $\mathrm{Bi}-\mathrm{O}$ and $\mathrm{O}-\mathrm{P}$ interactions in the first shell of the interacting $\mathrm{Bi}^{3+}$ ions.

The role played by anionic ligands in the structural distortion and stereo-activity of the lone-pairs was intensively discussed [32] and finds a major origin from the primary antibonding $\mathrm{Bi} 6 \mathrm{~s}-\mathrm{O} 2 \mathrm{p}$ interactions, with $\mathrm{Bi} 6 \mathrm{p}$ orbitals contribution also. This scheme occurs on the HOMO level (assigned to the LP electronic contribution) calculated for monomeric units shown Fig. 3a with strong Bi, $\mathrm{s}$ and $\mathrm{p}$ contributions. The analysis of the molecular orbital in the dimers is relevant to reveal the $\mathrm{Bi}---\mathrm{Bi}$ interactions, through bonding $\sigma$-type overlaps in the deep core levels, i.e. $\sim-9 \mathrm{eV}$ from its antibonding $\sigma^{*}$ contribution which is the HOMO at the Fermi level. It suggests the creation of weak $\mathrm{Bi}$-Bi interactions, as pictured in the electron localization function (ELF) map shown Fig. 1. Note that in the case of the AP phase, the electronic anisotropy around $\mathrm{Bi}^{3+}$ is less pronounced. A more realistic analysis of the complete periodic solid was performed after DFT calculations. Note that the coupling between the electron orbital spin polarized ferromagnetic configuration between $\mathrm{Ni}^{2+}$ centers was used, preserving the cell symmetry, with respect to the most important $\mathrm{Ni}-\mathrm{Ni}$ exchange found FM in the AP-form and expected similar in the HP-one, see below. We did not used spin orbit coupling (SOC) between the electron orbital with its spin moment generated by heavy nuclei, such as bismuth. 
The main features of the LDA+U density of states (DOS, Fig. 3b,c) are typical for bismuth transition metal phosphates [4] and conserve the same topology for both the AP and HP-polymorphs. The coordinates deduced from the relaxation are presented in Table 1 and compared with those deduced from the Rietveld refinement.

a)

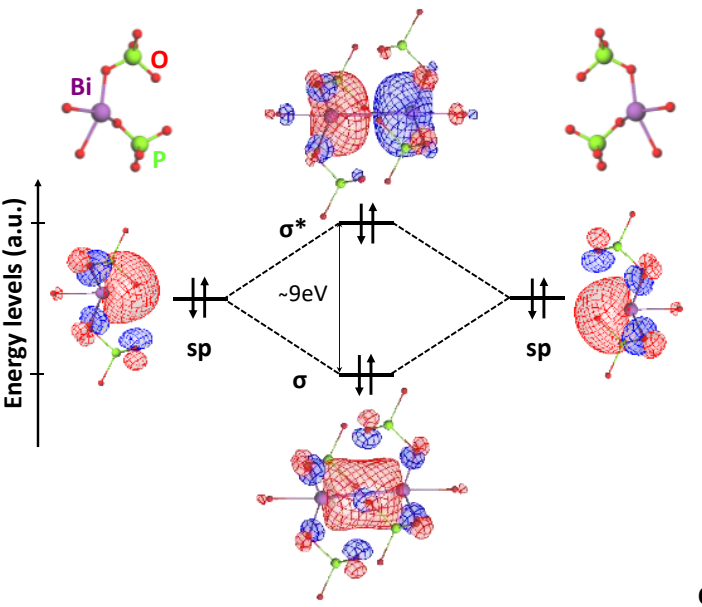

b)

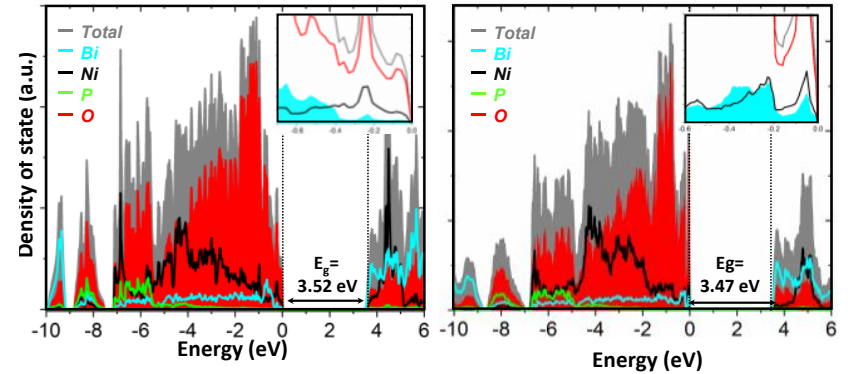

Fig. 3. a) EHTB molecular orbitals for $\mathrm{BiO}_{3}\left(\mathrm{PO}_{4}\right)$ and $\mathrm{Bi}_{2} \mathrm{O}_{6}\left(\mathrm{PO}_{4}\right)_{2}$ with creation of $\sigma$ and $\sigma^{*}$ levels, total and atomic resolved projected DOS calculated for b) the AP-BNPO and c) the HP-BNPO. The Fermi level is set to 0 .

Essentially, the top of the broad valence band (VB) are a mixture of $\mathrm{Ni}, \mathrm{Bi}$ and $\mathrm{O}$ states with small contribution of the $\mathrm{P}$ states. These bands lie between $\sim-7 \mathrm{eV}$ and $\mathrm{EF}_{\mathrm{F}}$ and account essentially for the bonding within the 1D-chains and with their surrounding oxygen ligands. Only the lowest part of VB shows an appreciable contribution of $\mathrm{P} 3 p$ orbitals within the strongly covalent $\mathrm{P}-\mathrm{O}$ bonds. The magnetic Ni $3 d$ orbitals lie between $-2 \mathrm{eV}$ and unoccupied $\mathrm{Ni} d$ states, $\mathrm{O} 2 p$ and $\mathrm{Bi} 6 p$ and $6 s$ states form the bottom of the conduction band $(\mathrm{CB})$. The compounds presented have very similar bandgap calculated dictated by the similar $[\mathrm{OBiNi}]^{3+}$ trans-chains. Comparing the Fermi levels (see the insets of Fig. $3 b$ and $3 c$ ) of the AP- and HP- forms highlights a sharpest $\mathrm{Bi}$ contribution for the HP-polymorph, while Ni d states are found in AP-BNPO. The molecular orbital features found in TBHE are rather well reproduced giving the large $\mathrm{Bi}$ contribution around $-9 \mathrm{eV}$ (assigned to the bonding $(\mathrm{Bi}-\mathrm{Bi})_{\mathrm{a}}$ together with $\sigma^{*} \mathrm{Bi}-\mathrm{O}$ levels, and the $\mathrm{Bi}$ levels at $\mathrm{E}_{\mathrm{F}}$ consistent with the HOMO level which comfort the direct bismuthbismuth interaction.

After PAW-DFT calculations, we further performed crystal orbital Hamilton population (COHP) analyzes to gauge the nature and bonding strengths in the HP-polytype, focusing on (Bi-Bi) $)_{\mathrm{a}}$ and $(\mathrm{Bi}-$ $\mathrm{Bi})_{b}$ contacts. Some examples for this process are given in [33], [34]. For a reference, we also calculated the projected COHP (pCOHP) for the shortest Bi-O1 bond of $2.16 \AA$ after ionic relaxation. The Fig. 4 gives the obtained bonding patterns. Bonding and antibonding interactions are represented by negative and positive values of the COHP, while non-bonding return zero values.

For $(\mathrm{Bi}-\mathrm{Bi})_{\mathrm{a}}$, bonding interactions dominate the entire range of valence-bands apart from the strong antibonding region starting $1 \mathrm{eV}$ below the fermi level. This situation is mixed in the (Bi-Bi)b case but with much weaker projected-COHP intensities, due to the absence of significant orbital overlap. The cumulative integrated I-COHP values at the Fermi level are -0.89 for the (Bi-Bi)a and $(\mathrm{Bi}-\mathrm{Bi})_{\mathrm{b}}$ respectively giving a net bonding capacity for both but strongest through the LP overlap. Comparatively Bi-O1 has a strong covalent bonding character in the full VB giving a superior ICOHP value of -4.2 at $\mathrm{E}_{\mathrm{F}}$. It allows assigning to (Bi-Bi) a weak bonding character, according to the method used here.

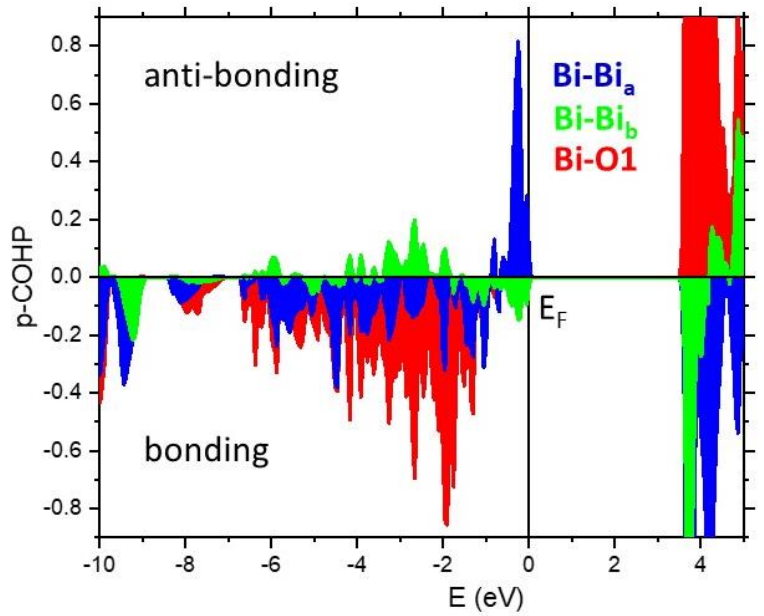

Fig. 4. Crystal orbital Hamilton populations (COHPs) of the HP-BNPO for $\mathrm{Bi}^{-} \mathrm{Bi}_{\mathrm{a}}$ (blue), $\mathrm{Bi}^{-} \mathrm{Bi}_{\mathrm{b}}$ (green) and $\mathrm{Bi}-\mathrm{O}_{1}$ (red). The Fermi level is set to $0 \mathrm{eV}$.

HT stability

An in-situ X-ray diffraction study versus temperature was performed under air in order to check the stability of the HP-phase. Results are gathered on Fig. 5a, and the evolution of the refined unit cell parameters for both phases are displayed Fig. S2 and S3 in ESI. The HP-form starts to transform back into the AP-form above $\sim 700{ }^{\circ} \mathrm{C}$ in air, but remains significant up to $950{ }^{\circ} \mathrm{C}$. Again, this follows the same process largely detailed in [11] and involving a probable $1^{\text {st }}$ order transition, as it led to the co-presence of the two polymorphs in an extended thermal range (Fig. 5b). Plotting the unit cell volume reduced per formula unit as a function of temperature gives two distinct thermal expansion coefficients of $36 \times 10^{-6}$ (HP-BNPO) and $29 \times 10^{-6}{ }^{\circ} \mathrm{C}^{-1}$ (AP-BNPO) respectively (Fig. 5c). However, the $\mathrm{V}(\mathrm{T})$ plot of the HP form shows an inflexion around $700{ }^{\circ} \mathrm{C}$, i.e. at the HP $\rightarrow$ AP transformation temperature. Here, $V_{\text {HP- }}$ $700^{\circ}$ reaches $\mathrm{V}_{\mathrm{AP}-\mathrm{RT}}$ (see grey arrow on Fig. 5c) where the two forms compete. It is plausible that, up to this point, the internal chemical pressure is relaxed until a $1^{\text {st }}$ order transformation into the AP-form. 


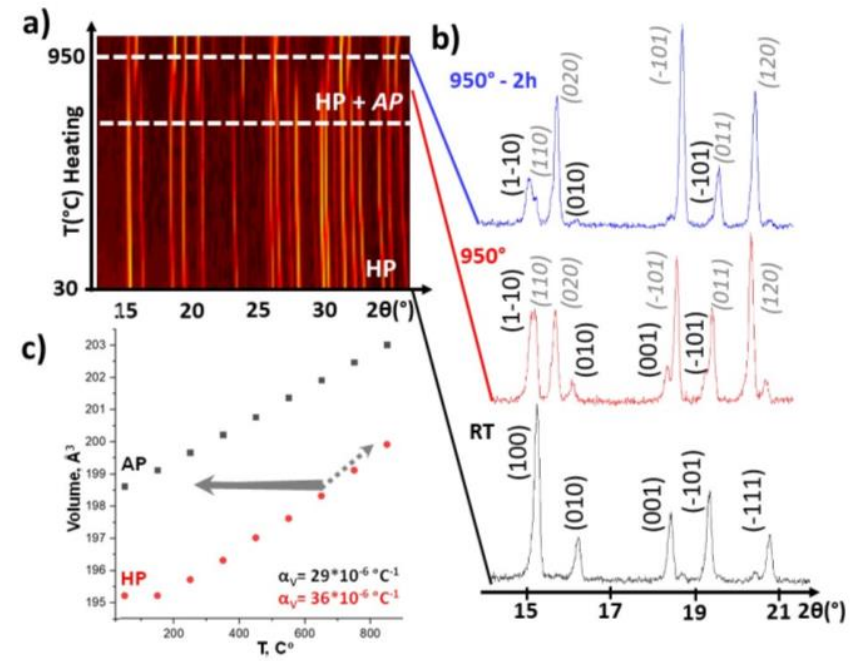

Fig. 5. a) HT-XRD of HP-BNPO. b) Patterns collected at RT (black), at $950{ }^{\circ} \mathrm{C}$ (red) and $950{ }^{\circ} \mathrm{C}$ after $2 \mathrm{~h}$ (blue) correspond to HP-BNPO (hkl in bold) and HP-AP ( $h k l$ in italic) mixtures c) plots of the volume per formula unit versus temperature for the two forms. The grey line corresponds to the minimal volume identical between HP and AP forms.

\section{Magnetic properties}

The magnetic properties of AP-BNPO were largely detailed in [5] including a magnetic phase diagram function of the relative magnetic exchanges $\underline{J}$ s. From the magnetic structure refined from powder neutron diffraction (PND) the role of the robust ferromagnetically coupled edge-sharing $\mathrm{Ni}_{2} \mathrm{O}_{10}$ dimers inside the chains are predominant, while weakest antiferromagnetic inter-dimer super-super exchanges order below $\mathrm{T}_{\mathrm{N}}=17.5 \mathrm{~K}$. Due to the preservation of the oxo-centered units in HP-BNPO, the edge-sharing $\mathrm{Ni}_{2} \mathrm{O}_{10}$ remains, but significantly distorted see Fig. 6a. It is striking that the Ni-Ni distance is increased under pressure $\left(\mathrm{d}_{\mathrm{AP}}=3.1715 \AA\right.$ and $\mathrm{d}_{\mathrm{HP}}=3.2533 \AA$ ) but the $\mathrm{Ni}-\mathrm{O}-\mathrm{Ni}$ angle remain in the orthogonal configuration $\left(\mathrm{Ni}-\mathrm{O}-\mathrm{Ni}_{\mathrm{AP}}=99.87^{\circ}\right.$ versus $\left.\mathrm{Ni}-\mathrm{O}-\mathrm{NiHP}=97.58^{\circ}\right)$ in favor of ferromagnetic exchanges between $\mathrm{S}=1 \mathrm{Ni}^{2+}$ ions from Kanamori-Goodenough rules. It leads to very similar magnetic behavior for HP-BNPO, as shown on the $\chi(\mathrm{T})$ and $\chi^{-1}(\mathrm{~T})$ plot of Fig. $6 \mathrm{~b}$. It shows a paramagnetic regime above $\mathrm{T}_{\mathrm{N}}=16.7 \mathrm{~K}$, characterized by a Curie Weiss law $\chi=C /\left(T-\theta_{\mathrm{Cw}}\right)$ with $\theta_{\mathrm{CW}}=-28.0 \mathrm{~K}$ and $\mu_{\mathrm{eff}}=3.29 \mu_{\mathrm{B}} / \mathrm{Ni}^{2+}$ which denotes a significant but rather common orbital contribution. Here again from Goodenough Kanamori rules the exchanges inside the dimers are expected FM. The mean field approach allows estimation of the mean inter-chain exchanges, using $\theta_{\mathrm{CW}}=\Sigma_{\mathrm{i}} \mathrm{Z}_{\mathrm{i}} \mathrm{S}(\mathrm{S}+1) \mathrm{J}_{\mathrm{i}} / 3 \mathrm{~K}_{\mathrm{b}}$, where $\mathrm{S}=2$ for $\mathrm{FM} \mathrm{Ni}_{2} \mathrm{O}_{6}$ dimers and $\mathrm{Z}=12$ is the number of connected neighbors by SSEs, see Fig. S4 in ESI for additional representations. It leads to $\mathrm{J}_{\text {inter }} / \mathrm{K}_{\mathrm{b}}=-1.16 \mathrm{~K}$. Compared to AP-BNPO $\left(\theta_{\mathrm{CW}}=-11.5 \mathrm{~K}, \mathrm{Z}=14\right)$ the $\mathrm{J}_{\text {inter }} / \mathrm{Kb}$ value of $-0.41 \mathrm{~K}$ is well scaled by Ni-Ni interatomic distances in the compact HP-BNPO (4.7 to $5.6 \AA$ along the SSE paths against 5.2 to 5.7 $\AA$ for AP-BNPO. The $\mathrm{M}(\mathrm{H})$ plots at various temperatures, displayed Fig. 6c, show a robust antiferromagnetic state $\mathrm{M}=0.28$ $\mu \mathrm{B} / \mathrm{FU}$ at $2 \mathrm{~K}$. A slight deviation from linearity at $\mu_{0} . \mathrm{H}_{\mathrm{c}}=6 \mathrm{~T}$ suggest a slight metamagnetic accident probably by surpassing one of the multiple $\mathrm{J}$ inter between FM-dimers. We note that according to the energy of a spin in a magnetic field $\mathrm{H}$ given by g.H. $\mu$ в.S (where the Landé factor $\mathrm{g} \sim 2, \mu \mathrm{B}=0.672 \mathrm{~J} / \mathrm{T}$ and $\mathrm{S}=2$ for robust spin dimers), we found and energy of $\sim 16 \mathrm{~K}$ close to the $T_{N}$ at zero-field. It validates a specific magnetic transition at $\mathrm{Hc}$ with emphasized alignment of $S=2$ macro spins along the external field.
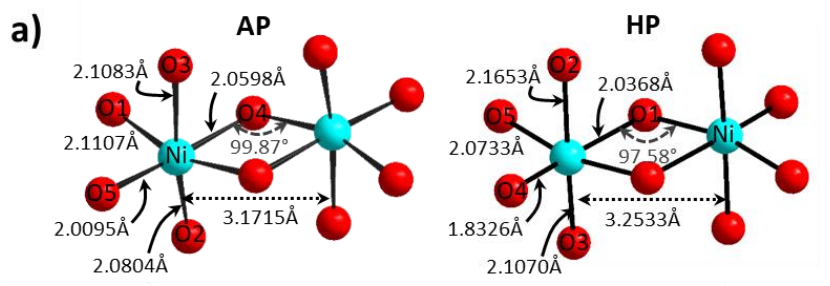

b)

c)
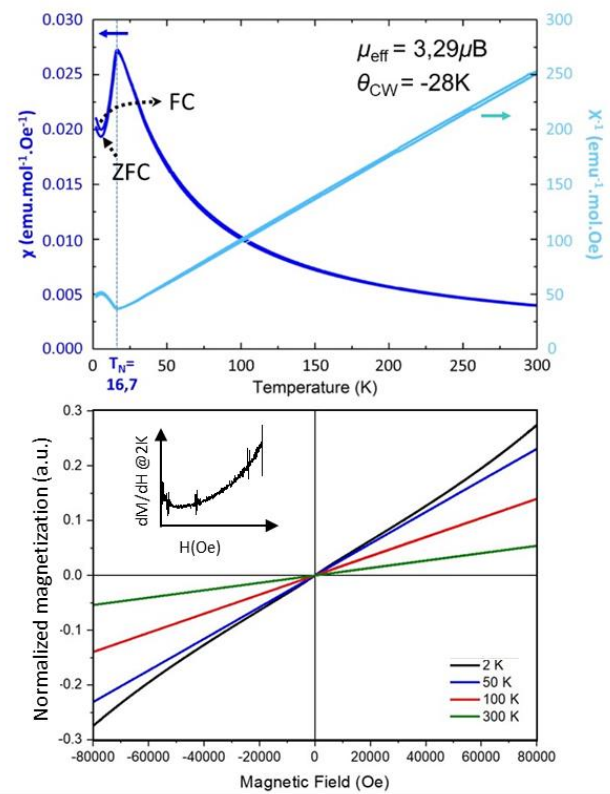

Fig. 6. a) Structural evolution of dimers between AP and HPBNPO, b) ZFC-FC magnetic susceptibility (dark blue) and inverse susceptibility (light blue) of $\mathrm{HP}_{-} \mathrm{BiNiPO}_{5}$ as a function of temperature. The magnetic field is set to $0.1 \mathrm{~T} \mathrm{c}$ ) field dependence of the magnetization of $\mathrm{HP}_{-} \mathrm{BiNiPO}_{5}$ at selected temperatures, and in insert, its derivative at $2 \mathrm{~K}$.

Conclusion

To summarize, similarly to HP-BCPO, [11] HP-BNPO prepared at $600{ }^{\circ} \mathrm{C}$ and $\mathrm{P}=5 \mathrm{GPa}$ adopts the crystal structure of the arsenate variant $\mathrm{BNAO}$. The chemical pressure drop after replacement of $\mathrm{AsO}_{4}$ by smaller $\mathrm{PO}_{4}$ is compensated by physical pressure and allows to stabilized this metastable form. The creation of short weakly bonding $\mathrm{Bi}^{3+}---\mathrm{Bi}^{3+}$ contacts were examined by Tight binding Hückel and Crystal orbital Hamilton populations analysis. Upon heating the pressure is relaxed until the volume of the APform is reached, returning a plausible $1^{\text {st }}$ order HP-BNPO $\rightarrow$ AP$\mathrm{BNPO}$ transition around $700^{\circ} \mathrm{C}$. Such chemical pressure compensation by high pressure route opens a wide route towards the prediction and stabilization of new tailor-made materials, in various chemical systems. According to the structural analogy between the 
$\mathrm{HP}$ and AP variants, it is striking that the robust preserved structural units are hold by oxo-centered principles. [1]

\section{ASSOCIATED CONTENT}

\section{Supporting Information}

The Supporting Information is available free of charge on the ACS Publications website $\mathrm{xxxx}$ at DOI: $\mathrm{xxxx}$.

Materials preparation, characterization methods, computational details, Rietveld refinements and EDS analysis.

\section{- AUTHOR INFORMATION}

\section{Corresponding Author}

*E-mail: Marie.Colmont@ centralelille.fr

\section{Author Contributions}

The manuscript was written through contributions by all authors.

\section{Notes}

The authors declare no competing financial interests.

\section{ACKNOWLEDGMENT}

The Fonds Européen de Développement Régional (FEDER), CNRS, Région Nord Pas-de-Calais, and Ministère de l'Education Nationale de l'Enseignement Supérieur et de la Recherche are acknowledged as well as the X-Press team from Institut Néel (Murielle Legendre and Céline Goujon).

\section{- REFERENCES}

[1] S. V. Krivovichev, O. Mentré, O. I. Siidra, M. Colmont, et S. K. Filatov, Chem. Rev., 2013, 113, 6459-6535.

[2] M. Lü, A. Aliev, J. Olchowka, M. Colmont, M. Huvé, C. Wickleder and O. Mentré, Inorg. Chem., 2014, 53, 12058-12065.

[3] J. Olchowka, M. Colmont, H. Kabbour, and O. Mentré, $J$. Alloys Compd., 2017, 709, 373-380.

[4] J. Olchowka, O. Mentré, H. Kabbour, M. Colmont, M. Adlung, M. Suta and C. Wickleder, Chem. - Eur. J., 2017, 23 , 15694-15703.

[5] O. Mentre, F. Bouree, J. Rodriguez-Carvajal, A. El Jazouli, N. El Khayati, et E. M. Ketatni, J. Phys. Condens. Matter, 2008, 41, 415211.

[6] B.-G. Jeon, B. Koteswararao, C.B. Park, G.J. Shu and S.C. Riggs, Sci. Rep., 2016, 6, n ${ }^{\circ} 1$.

[7] O. Mentré, E. Janod, P. Rabu, M. Hennion, F. LeclercqHuge, J. Kang, C. Lee, M.H. Whangbo and S. Petit, Phys. Rev. B, 2009, 80, 180413.
[8] O. Mentré, E. M. Ketatni, M. Colmont, M. Huvé, F. Abraham, et V. Petricek, J. Am. Chem. Soc., 2006, 128, 10857-10867.

[9] Y. Kohama, S. Wang, A. Uchida, K. Prsa, S. Zvyagin, Y. Skourski, R.D. McDonald, L. Balicas, H.M. Ronnow, C. Rüegg, M. Jaime, Phys. Rev. Lett., 2012, 109, nº 16.

[10] Y. Kohama, K. Mochidzuki, T. Terashima, A. Miyata, A DeMuer, T. Klein, C. Marcenat, Z.L. Dun, H. Zhou, G. Li, L. Balicas, N. Abe, Y.H. Matsuda, S. Takeyama, A. Matsuo and K. Kindo, Phys. Rev. B, 2014, 90, nº 6.

[11] M. Colmont, C. Darie, A. A. Tsirlin, A. Jesche, C. Colin, et O. Mentré, Inorg. Chem., 2018, 57, 6038-6044.

[12] J. Boje et Hk. Müller-Buschbaum, Z. Für Anorg. Allg. Chem., 1993, 619, 521-524.

[13] Z. Pei, A. van Dijken, A. Vink, et G. Blasse, J. Alloys Compd., 1994, 204, 243-246.

[14] I. Radosavljevic, J. A. K. Howard, et A. W. Sleight, Int. J. Inorg. Mater., 2000, 543-550.

[15] X. Xun, A. Yokochi, et A. W. Sleight, J. Solid State Chem., 2002, 168, 224-228.

[16] A. C. Roberts, P. C. Burns, R. A. Gault, A. J. Criddle, M. N. Feinglos, et J. A. R. Stirling, Eur. J. Mineral., 2001, 13, 167-175.

[17] Ketatni M., Abraham F., et Mentre O., Solid State Sci., 1999, 449-460, 1999.

[18] J. B. Goodenough, Magnetism and the chemical bond. Huntington, N.Y.: R. E. Krieger Pub. Co, 1976.

[19] V. Petrríček, M. Dušek, et L. Palatinus, Z. Für Krist. - Cryst. Mater., 2014, 229, 1737.

[20] P. E. Blöchl, Phys. Rev. B, 1994, 50, 17953-17979.

[21] Kresse, G. et J. Furthmüller, « Vienna Ab-initio Simulation Package (VASP) ». 2012.

[22] K. Koepernik et H. Eschrig, Phys. Rev. B, 1999, 59, p. 1743-1757.

[23] J. P. Perdew, K. Burke, et M. Ernzerhof, Phys. Rev. Lett., 1996, 77, 3865-3868.

[24] S. Maintz, V. L. Deringer, A. L. Tchougréeff, et R. Dronskowski, J. Comput. Chem., 2016, 37, 1030-1035.

[25] D. Dai, J. Ren, W. Liang, et M. H. Whangbo, «SAMOA (Structure and Molecular Orbital Analyzer) program package », 2002. http://chvamw.chem.ncsu.edu/

[26] D. Endara, M. Colmont, M. Huvé, G. Tricot, L. Carpentier, et O. Mentré, Inorg. Chem., 2012, 51, 4438-4447.

[27] M. Sturza, F. Han, C. D. Malliakas, D. Y. Chung, H. Claus, et M. G. Kanatzidis, Phys. Rev. B, 2014, 89, 054512.

[28] P. Cucka et C. S. Barrett, Acta Crystallogr., 1962, 15 , 865-872.

[29] F. Calderazzo, R. Poli, et G. Pelizzi, J. Chem. Soc. Dalton Trans., 1984, 11, 2365

[30] S. C. Critchlow et J. D. Corbett, Inorg. Chem., 1982, 21, 3286-3290

[31] S. Wang, D. B. Mitzi, G. A. Landrum, H. Genin, et R. Hoffmann, J. Am. Chem. Soc., 1997, 119, 724-732.

[32] J. Yang et M. Dolg, Phys. Chem. Chem. Phys., 2007, 9, 2094.

[33] W.-L. Li, C. Ertural, D. Bogdanovski, J. Li, et R. Dronskowski, Inorg. Chem., 2018, 57, 12999-13008.

[34] S. Steinberg et R. Dronskowski, Crystals, 2018, 8, 225. 